\title{
Potential zeolites related to faujasite (FAU): structures and energetics.
}

Olaf Delgado-Friedrichs ${ }^{a}$, Martin D. Foster ${ }^{b}$, Michael O'Keeffe ${ }^{c}$ and Michael M. J. Treacy ${ }^{d, *}$

aDepartment of Applied Mathematics, Australian National University, Canberra, ACT 2601, Australia.

${ }^{b}$ U.S. Bank, 400 N. Executive Drive, Brookfield, Wisconsin 53005, USA

${ }^{c}$ School of Molecular Sciences, Arizona State University, Tempe, Arizona 85287, USA

${ }^{d}$ Department of Physics, Arizona State University, Tempe, Arizona 85287, USA

\begin{abstract}
We describe five new zeolitic framework types, fav, faw, fax, fay and sod-t that are structurally related to faujasite. They are derived from isomorphic expansions of the tetrahedral nets associated with selected Frank-Kasper phases. Each tetrahedral vertex of the net is replaced by a sodalite cage $(\mathrm{S})$ and each edge by a hexagonal prism $(\mathrm{P})$, in effect replacing each vertex with an $\mathrm{SP}_{4}$ tetrahedron. Faujasite itself, framework type FAU, is an $\mathrm{SP}_{4}$ expansion of the diamond net.

In the Frank-Kasper phases the periodic incorporation of icosahedra, which can be subdivided into twenty almost-regular tetrahedral volumes, tends to minimize distortion of the associated tetrahedral $\mathrm{SP}_{4}$ framework, ensuring low framework energies. The computed framework energy of silicate fav compares most favorably with that for FAU and EMT, presenting an appealing zeolite synthesis target.
\end{abstract}

\section{Introduction, terminology and definitions}

Zeolites with the faujasite framework are among the most valuable of inorganic materials in the economic sense. In this paper we explore related framework structures that are potential targets for synthesis and which might be equally valuable materials. We start with some definitions and terminology necessary for understanding the provenance of these new structures.

A simple polyhedron is one in which exactly two faces meet at each edge and three meet at each vertex. A simple tiling is a tiling of space by simple polyhedra in which exactly two polyhedra meet at each face, three at each edge and four at each vertex. Foams are simple tilings; so are the frameworks of many important zeolites. 
In a 3-dimensional tiling there is a dual tiling generated as follows. Place a new vertex in each old tile, connect these through faces to the new vertices in adjacent tiles. Now recognizing that the dual of a dual is the original tiling, the old vertices are in the new (dual) tiles and the old edges pass through the new faces. For our purpose we note that the dual of a simple tiling is a tiling by tetrahedra and vice versa.

The set of edges and vertices of a tiling (the 1-skeleton) form a net. Nets of interest in structural chemistry are assigned a three-letter (bold, lower-case) RCSR code xyz. ${ }^{1}$ If it is the approved net of a known zeolite it is assigned an IUPAC (bold, upper-case) code XYZ by the Structure Commission of the International Zeolite Association. ${ }^{2}$ In the case of faujasite the zeolite framework type code is FAU. In RCSR the same net is identified as fau.

We are concerned here with the linking of groups with tetrahedral shape in which the linkage is either staggered with an inversion center between the two groups, or eclipsed with a (local) mirror between the two parts. Specifically, linking vertices with four edges and linking truncated octahedra with hexagonal-prism edges, with minimal torsional stress, as shown in Figure 1.

In the approach to tiling by the Dress group ${ }^{3,4}$ tiles are split into tetrahedral chambers in which the vertices are at a vertex of the tile, in the center of an adjacent edge, in the center of an adjacent face and in the center of the tile. The set of chambers of the tiling form a tiling by tetrahedra. The dual of this tiling is a simple tiling with a net we call the "-t net". These are useful for studying the periodic surfaces associated with a net. ${ }^{5}$ For the present purpose we note that if the original tiling is simple, in the zeolitic form of the $-\mathbf{t}$ structure the $\mathrm{SiO}_{4}$ tetrahedra (with $\mathrm{Si}$ at the vertices and $\mathrm{O}$ on the edges) are replaced by truncated octahedra (sodalite cages, $\mathrm{S}$ ) and the edges ( $\mathrm{O}$ atoms) replaced by hexagonal prisms (P) to form $\mathrm{SP}_{4}$ units (Fig. 1). This is exactly what we want to find structures related to FAU. Note that the number of different (unrelated by symmetry) chambers, $D$, in the tiling is the flag transitivity and is reported as $D$ size in RCSR ( $D$ from Delaney-DressDelgado symbol). It follows that a $-\mathbf{t}$ net is vertex $D$-transitive.

The next question is which nets to select to make viable FAU-related structures. Linking tetrahedral vertices in all-staggered conformation leads inexorably to the diamond net (dia). Staggered linking of truncated octahedra with trigonal prisms similarly produces the FAU framework (Figure 2).

A "cousin" of FAU, namely EMT, is known as a zeolite (Figure 3). This has the lonsdaleite (lon) underlying net, which can be augmented with $\mathrm{SP}_{4}$ units, preserving the local tetrahedral 
symmetry of the truncated octahedron and four joined hexagon prisms. Only one quarter of the junctions are in the eclipsed conformation but there is no intrinsic stress penalty introduced by this eclipsed versus staggered packing.

Linking in an all-staggered conformation is not possible with strictly regular conformation, but it can be shown readily ${ }^{6,7}$ that, with a small deformation, five such groups can be linked to form a low-stress pentagon (the angle in a regular pentagon is $108^{\circ}$ whereas the tetrahedral angle is $\left.109.47^{\circ}\right)$. Ideally, to continue further the assembly would form a simple tiling by tiles with pentagonal faces. However, a tiling by pentagonal dodecahedra fits on the 3-sphere and to make a simple tiling in flat 3D space, 6-rings are inevitable. In terms of the dual structure it is noted that tilings by tetrahedra in which five tetrahedra meet at every edge is impossible, and there must be some edges where six tetrahedra meet. Such structures are the basis for the celebrated FrankKasper intermetallic compounds. ${ }^{8}{ }^{9}$ It has been shown rigorously that there are just two simple possibilities that are tile 3-transitive. ${ }^{10}$ These correspond to the $\mathrm{MgCu}_{2}$ and $\mathrm{Cr}_{3} \mathrm{Si}$ Frank-Kasper phases. Relevant to our discussion is the fact that the dual simple structures are those of the zeolite frameworks MTN and MEP respectively. The fraction of 6-rings is smallest in MTN (1/10 compared to 1/9 for MEP). The augmented -t nets corresponding to these two (Figure 4) have symbols fav ("mtn-t", vertex transitivity 17) and faw ("mep-t", vertex transitivity 23).

A related common intermetallic structure based on packing tetrahedra is the extended (14coordinated) body-centered cubic bcu-x. In this structure either four or six tetrahedra meet at an edge. The dual structure is the familiar sodalite (SOD) framework constructed of polyhedra with 4- and 6-rings. The absence of 5-rings suggests that, after expansion, the $\mathrm{SP}_{4}$ tetrahedral groups will be more strained. For comparison, we include this -t net $\mathrm{SP}_{4}$ expansion, sod-t (vertex transitivity 3), as a FAU analog (Figure 5).

\section{Framework energy calculations}

Upon close inspection (Figure 4, and Tables 2-4), the fav (symmetry $F d \overline{3} m$ ), faw (symmetry $P m \overline{3} n$ ), and sod-t (symmetry $\operatorname{Im} \overline{3} m$ ), structures exhibit small, but discernible, deformations to the sodalite and double 6-ring cages, suggesting that the silicate framework energies may be higher than the relatively unstrained FAU and EMT frameworks. To explore this energetic penalty, the frameworks were relaxed at constant pressure conditions by the General Utility Lattice Program (GULP) ${ }^{11,12}$ using the Sanders-Leslie-Catlow potential ${ }^{13}$ for $\mathrm{SiO}_{2}$, and the results are presented in 
Table 1. To five significant figures the fav framework has framework energy $-128.45 \mathrm{eV} / \mathrm{SiO}_{2}$, slightly higher than that for FAU and EMT $\left(-128.50 \mathrm{eV} / \mathrm{SiO}_{2}\right)$. The faw framework has higher energy, $-128.38 \mathrm{eV} / \mathrm{SiO}_{2}$, and the sod-t energy of $-128.33 \mathrm{eV} / \mathrm{SiO}_{2}$ is higher yet. For comparison, the quartz framework is $-128.64 \mathrm{eV} / \mathrm{SiO}_{2}$. These energies fall within the normal range for many known zeolites when modeled as silicates. ${ }^{14}$ Compared to FAU and EMT, GULP reported that fav and faw exhibited stronger core-shell polarization of some oxygen atoms. Further, in full symmetry, phonon modes with negative eigenvalues, $\omega^{2}$, occurred, suggesting that the structures are metastable and may be more stable under a lower symmetry, or possibly with mixed composition, such as an alumino- or germano-silicate. Negative eigenvalues arise for a number of normal zeolite structures, one example being MTN itself, and do not necessarily disqualify a framework from the realms of plausibility. We did not explore these avenues further.

We note in passing that the framework of zeolite tschörtnerite, TSC, is also built from $\mathrm{SP}_{4}$ units, but it is not an $\mathrm{SP}_{4}$ augmentation of a $-\mathbf{t}$ net, as investigated here: the double 6-ring prisms (P) in TSC do not correspond to edges of a $-\mathbf{t}$ net. $\mathrm{SP}_{4}$-augmented $\mathbf{- t}$ nets will have, on average, two hexagonal prisms to each sodalite, for a "composition" of $\mathrm{SP}_{2}$, but the "composition" of TSC is $\mathrm{SP}_{4}$. Nevertheless, it is worth noting that the framework energy of $\mathbf{T S C}$ is $-128.50 \mathrm{eV} / \mathrm{SiO}_{2}$, comparable to FAU and EMT, indicating that the $\mathrm{SP}_{4}$ units are minimally stressed in TSC.

We note that fav, which is built on the MTN framework with the most 5-rings (9 out 10), has a more favorable energy than faw, which is built on the MEP framework with lightly fewer 5rings ( 8 out of 9). sod-t, based on the SOD framework with no 5-rings has even higher energy, as expected. Comparison of framework energies of FAU and EMT confirms there is no intrinsic penalty for the eclipsed configuration of the $\mathrm{SP}_{4}$ units.

\section{Descriptions of the structures}

The tiles of the "parent" structures define cages (e.g. the adamantane cage in the dia structure, shown in Fig. 6). In the FAU-related family, we have described the vertices of the parent net as being replaced by a truncated octahedron, and the edges by hexagonal prisms (forming the $\mathrm{SP}_{4}$ unit). Alternatively, we can describe the transformation as replacing the vertices of the tiles by a hexagonal prism of vertices. Thus, the adamantane cage of dia transforms into the faujasite cage of FAU (Fig. 2). The generation of the cages in sod-t, fav, and faw is shown in Fig. 6. Note that 
mtn and mtp have two tiles each, one of which is the pentagonal dodecahedron. The corresponding cage in fav and faw is the 120-vertex Archimedean polyhedron ild with icosahedral symmetry.

The tile in SOD (the parent of sod-t) is a truncated octahedron (tro in RCSR); in sod-t it becomes the polyhedron (tro-e-a) with 144 vertices (Fig 6). MTN and MEP (parents of fav and faw) each contain two kinds of tile. In MTN they are two dodecahedra [5 $\left.5^{12}\right]$ and one hexakaidecahedron $\left[5^{12} \cdot 6^{4}\right]$. In MEP the tiles are one dodecahedron [5 $\left.{ }^{12}\right]$ and three tetrakaidecahedra $\left[5^{12} \cdot 6^{2}\right]$. Noteworthy is that the cage derived from the dodecahedron has icosahedral symmetry and is the largest Archimedean polyhedron - the truncated icosidodecahedron (tid).

The GULP-refined coordinates for fav, faw and sod-t are given in tables 2,3 and 4 respectively.

\section{Discussion and Conclusions}

It is tempting to infer that every regular-tetrahedral (zeolitic) net can be subjected to such an isomorphic transformation by augmenting vertices of the -t net with $\mathrm{SP}_{4}$ units. However, most zeolitic nets augmented this way will strain the $\mathrm{SP}_{4}$ units, raising the framework energy above the bounds of feasibility. In a silicate $\mathrm{SiO}_{4}$ tetrahedron, for example, the $\mathrm{Si}-\mathrm{O}-\mathrm{Si}$ angles tend to be in the range $140^{\circ}$ to $<180^{\circ}$. However, the $\mathrm{S}-\mathrm{P}-\mathrm{S}$ angle is constrained to be near $180^{\circ}$. Thus, the existence of a viable silicate net does not ensure a viable $\mathrm{SP}_{4}$ augmentation. As we show here, two exceptions are the MTN and MEP frameworks, which are based on the simplest Frank-Kasper phases. The key is that these frameworks are rich in regular 5-rings, with angles of $108^{\circ}$ between edges, which closely matches the tetrahedral angle of $109.47^{\circ}$ favored by the ideal $-\mathbf{t}$ net, while allowing S-P-S angles to be close to $180^{\circ}$. Consistent with the fact that MTN has a slightly higher 5-ring to 6-ring ratio than does MEP, 9/1 and 8/1 respectively, the fav (mtn-t) structure has a lower framework energy (less distortion) than the faw (mep-t) structure. SOD itself, having no 5rings, has more framework distortion and a concomitant higher framework energy.

The low energies of fav and faw lead us to ask if other -t nets derived from Frank-Kasper phase duals would be suitable candidates. The next-simple structure is that of the $\mathrm{Zr}_{4} \mathrm{Al}_{3}$ type, the dual of which is the clathrate variously known as type II or type IV (RCSR symbol isq). The tiling has $D$-size $=40$ implying that the $-\mathbf{t}$ net is vertex 40 -transitive. However, the plausibly-low framework energy for sod-t suggests that isolated (not edge-sharing) 4-rings might not impose too 
large an energy, so a search was made in RCSR for clathrates with $D$-size $<30$. This led to two more candidate structures. The first, alb-x-d $(D$-size $=16)$, is the dual of the $\mathrm{AlB}_{2}$ net, which is another intermetallic structure based on tetrahedron packing. ${ }^{15}$ The simple tiling is a packing of enneahedra $\left[4^{3} .5^{6}\right]$ and icosahedra $\left[5^{12} .6^{8}\right]$ ("hexagonal barrels"). The corresponding -t net has been assigned the symbol fax. The GULP energy of this, as an $\mathrm{SiO}_{2}$ framework, is $-128.26 \mathrm{eV} / \mathrm{SiO}_{2}$, which, although higher than FAU, is still plausible. Aspects of the structure are depicted in Fig. 7 and the coordinates are given in Table 5. Note the large cage, which suggests that synthesis might be effected with the aid of a large structure-directing template.

The other simple tiling from the RCSR search, isq, is an isohedral tiling first described many years ago. ${ }^{16,17}$ This has $D$-size 18 and yields a -t net assigned symbol fay. The framework energy is $-128.22 \mathrm{eV} / \mathrm{SiO}_{2}$, which is the highest framework energy of the structures studied here. The structure is shown in Fig. 8, and the coordinates are given in Table 6.

The energetic plausibility of the fav framework, and possibly the faw and sod-t frameworks, which are closely related to the FAU framework, presents an interesting synthetic challenge to the zeolite community. This challenge is not dissimilar to the possibilities raised by Breck ${ }^{18}$ when he conjectured on the possibility of the hypothetical 'Structure 6', or 'hexagonal faujasite', which was later successfully synthesized as the framework type EMT. ${ }^{19}$

We note also, relevant in this context, the design and successful synthesis of large cubic zeolites based on the building units of the RHO structure. ${ }^{20,21}$ 


\section{References}

1. O'Keeffe, M.; Peskov, M. A.; Ramsden, S. J.; Yaghi, O. M., The Reticular Chemistry Structure Resource (RCSR) Database of, and symbols for Crystal Nets. Acc. Chem. Res. 2008, 41, 17821789.

2. Baerlocher, C.; McCusker, L. B.; Olson, D. H., Atlas of Zeolite Framework Types. 6 ed.; Elsevier Science: 2007.

3. Delgado-Friedrichs, O.; Dress, A. W. M.; Huson, D. H.; Klinowski, J., Nature 1999, 400, 644 647.

4. Dress, A. W. M.; Huson, D. H., On tilings of the plane. Geometriae Dedicata 1987, 24, 269296.

5. de Campo, L.; Delgado-Friedrichs, O.; Hyde, S. T.; O'Keeffe, M., Minimal nets and minimal minimal surfaces. Acta Crystallogr. 2013, A69, 483-489.

6. Howarth, A. J.; Li, P.; Farha, O. K.; O'Keeffe, M., Bottom-Up Design and Generation of Complex Structures. A New Twist in Reticular Chemistry. Cryst. Growth Des. 2018, 18, 449-455.

7. O'Keeffe, M., Tetrahedral frameworks $\mathrm{TX}_{2}$ with $\mathrm{T}-\mathrm{X}-\mathrm{T}$ angle $=180^{\circ}$. Rationalization of the structures of MOF-0500, and of MIL-100 and MIL-101. Mater. Res. Bull. 2006, 41, 911-915.

8. Frank, F. C.; Kasper, J. S., Complex Alloy Structures Regarded as Sphere Packings. 1 Definitions and Basic Principles. Acta Crystallogr. 1958, 11, 184-190.

9. Frank, F. C.; Kasper, J. S., Complex Alloy Structures Regarded as Sphere Packings. 2. Analysis and Classification of Representative Structures. 1959, 12, 483-499.

10. Delgado-Friedrichs, O; O'Keeffe, M., Simple tilings by polyhedra with 5- and 6-sided faces. Acta Crystallogr. 2010, A66, 237-239.

11. Gale, J. D., GULP - a computer program for the symmetry adapted simulation of solids. JCS Faraday Trans. 1997, 93, 629.

12. Gale, J. D.; Rohl, A. L., The General Utility Lattice Program. Mol. Simul. 2003, 29, 291-341.

13. Sanders, M. J.; Leslie, M.; Catlow, C. R. A., Interatomic potentials for $\mathrm{SiO}_{2}$. Journal of the Chemical Society-Chemical Communications 1984, (19), 1271-1273.

14. Dawson, C. J.; Pope, M. A. B.; O’Keeffe, M.; Treacy, M. M. J., Low-Density, Low-Energy, Zeolites Assembled from Double-Layer Silica Sheets. Chem. Mater. 2013, 25, 3816-3821.

15. Bonneau, C.; O’Keeffe, M., Intermetallic Crystal Structures as Foams. Beyond Frank-Kasper. Inorg. Chem. 2015, 54, 808-814. 
16. Williams, R. E., Space-filling polyhedron: its relation to aggregates of soap bubbles, plant cells, and metal crystallites. Science 1968, 161, 276-277.

17. O'Keeffe, M., Sphere Packings and Space Filling by Congruent Simple Polyhedra. Acta Crystallogr. 1998, A54, 320-329.

18. Breck, D. W., Zeolite Molecular Sieves: Structure, Chemistry, and Use. Robert E. Krieger Publishing Company: Malabar, Florida, 1974.

19. Dougnier, F.; Patarin, J.; Guth, J. L.; Anglerot, D., Synthesis, characterization, and catalytic properties of silica-rich faujasite-type zeolite (FAU) and its hexagonal analog (EMT) prepared by using crown-ethers as templates. Zeolites 1992, 12, 160-166.

20. Guo, P.; Shin, J.; Greenaway, A. G.; Min, J. G.; Su, J.; Choi, H. J.; Liu, L.; Cox, P. A.; Hong, S. B.; Wright, P. A.; Zou, X., A zeolite family with expanding structural complexity and embedded isoreticular structures. Nature 2015, 524, 74-78.

21. Shin, J.; Xu, H.; Seo, S.; Guo, P.; Min, J. G.; Cho, J.; Wright, P. A.; Zou, X.; Hong, S. B., Targeted Synthesis of Two Super-Complex Zeolites with Embedded Isoreticular Structures. Angew. Chem. Int. Ed. 2016, 55, 4928-4932. 
Table 1: Framework energies, $U$, per $\mathrm{SiO}_{2}$ for $\mathrm{SP}_{4}$-based zeolites computed using the SandersLeslie-Catlow silica empirical potential in GULP. The energy for quartz, qtz, is added for comparison. The energies are all within the range of the known zeolites when modeled as silicates. The diameter of the largest included sphere, $D_{i}$, and of the largest freesphere, $D_{f}$, indicate the cavity size and relative porosity of the structures.

\begin{tabular}{|c|c|c|c|}
\hline Code & $U(\mathrm{eV})$ & $D_{i}(\AA)$ & $D_{f}(\AA)$ \\
\hline qtz & -128.640 & 1.86 & 1.45 \\
TSC & -128.502 & 16.05 & 4.01 \\
FAU & -128.498 & 10.99 & 7.17 \\
EMT & -128.495 & 11.33 & 7.17 \\
fav & -128.451 & 23.49 & 7.73 \\
faw & -128.379 & 19.88 & 6.56 \\
sod-t & -128.333 & 20.38 & 7.61 \\
fax & -128.260 & 25.40 & 7.03 \\
fay & -128.218 & 13.88 & 7.00 \\
\hline
\end{tabular}


Table 2. Atomic coordinates for the fav (mtn-t) framework, optimized as a silicate by GULP in cubic space group $F d \overline{3} m$, with $a=64.696 \AA$.

\begin{tabular}{|c|c|c|c|c|c|c|c|}
\hline Atom & $x$ & $y$ & $Z$ & Atom & $x$ & $y$ & $Z$ \\
\hline Si1 & 0.09180 & 0.12450 & 0.55828 & $\mathrm{O} 14$ & 0.02511 & 0.02511 & 0.27747 \\
\hline $\mathrm{Si} 2$ & 0.23781 & 0.30396 & 0.33798 & O15 & 0.98915 & 0.03250 & 0.26085 \\
\hline $\mathrm{Si} 3$ & 0.28147 & 0.31496 & 0.34867 & O16 & 0.00755 & 0.06028 & 0.28475 \\
\hline $\mathrm{Si} 4$ & 0.22700 & 0.25977 & 0.32482 & O17 & 0.00724 & 0.15417 & 0.41645 \\
\hline $\mathrm{Si} 5$ & 0.00306 & 0.03598 & 0.28090 & O18 & 0.02127 & 0.19082 & 0.42544 \\
\hline Si6 & 0.02085 & 0.16699 & 0.43252 & O19 & 0.04405 & 0.15862 & 0.43183 \\
\hline $\mathrm{Si} 7$ & 0.03420 & 0.12513 & 0.36624 & $\mathrm{O} 20$ & 0.04160 & 0.13869 & 0.34683 \\
\hline $\mathrm{Si} 8$ & 0.07720 & 0.10991 & 0.37552 & $\mathrm{O} 21$ & 0.01453 & 0.11108 & 0.36141 \\
\hline $\mathrm{Si} 9$ & 0.04803 & 0.13989 & 0.32290 & $\mathrm{O} 22$ & 0.05232 & 0.10968 & 0.37379 \\
\hline Sil0 & 0.09161 & 0.12428 & 0.33221 & $\mathrm{O} 23$ & 0.02707 & 0.14102 & 0.38394 \\
\hline Sil1 & 0.06426 & 0.15129 & 0.44395 & $\mathrm{O} 24$ & 0.08 & 0.08653 & 0.37601 \\
\hline Si12 & 0.09157 & 0.12384 & 0.41906 & $\mathrm{O} 25$ & 0.08686 & 0.12246 & 0.35647 \\
\hline Si13 & 0.16974 & 0.25656 & 0.28993 & $\mathrm{O} 26$ & 0.08305 & 0.12231 & 0.39597 \\
\hline Si14 & 0.00827 & 0.12204 & 0.30532 & $\mathrm{O} 27$ & 0.04669 & 0.16383 & 0.31603 \\
\hline Si15 & 0.00607 & 0.15177 & 0.39188 & $\mathrm{O} 28$ & 0.07067 & 0.12962 & 0.31956 \\
\hline Si16 & 0.00561 & 0.21110 & 0.33529 & $\mathrm{O} 29$ & 0.03236 & 0.12656 & 0.30906 \\
\hline Si17 & 0.03341 & 0.18336 & 0.30795 & $\mathrm{O} 30$ & 0.08101 & 0.16899 & 0.44104 \\
\hline $\mathrm{O} 1$ & 0.10415 & 0.10415 & 0.55132 & $\mathrm{O} 31$ & 0.07295 & 0.12976 & 0.43464 \\
\hline $\mathrm{O} 2$ & 0.10723 & 0.14277 & 0.56482 & $\mathrm{O} 32$ & 0.10218 & 0.10218 & 0.42611 \\
\hline $\mathrm{O} 3$ & 0.07810 & 0.11925 & 0.57810 & $\mathrm{O} 33$ & 0.10844 & 0.14156 & 0.41925 \\
\hline $\mathrm{O} 4$ & 0.07776 & 0.13136 & 0.53895 & O34 & 0.16401 & 0.27092 & 0.27092 \\
\hline O5 & 0.21796 & 0.30868 & 0.35223 & $\mathrm{O} 35$ & 0.14987 & 0.24221 & 0.29360 \\
\hline O6 & 0.25748 & 0.30980 & 0.35187 & O36 & 0.99771 & 0.14027 & 0.29215 \\
\hline $\mathrm{O} 7$ & 0.23939 & 0.28033 & 0.33080 & $\mathrm{O} 37$ & 0.99577 & 0.12044 & 0.32672 \\
\hline O8 & 0.23662 & 0.31714 & 0.31714 & $\mathrm{O} 38$ & 0.01643 & 0.23357 & 0.33168 \\
\hline O9 & 0.29382 & 0.29382 & 0.34625 & O39 & 0.02077 & 0.19307 & 0.32712 \\
\hline $\mathrm{O} 10$ & 0.28530 & 0.32793 & 0.32793 & $\mathrm{O} 40$ & 0.98336 & 0.20964 & 0.32344 \\
\hline O11 & 0.22408 & 0.25909 & 0.30015 & O41 & 0.04956 & 0.20044 & 0.29892 \\
\hline $\mathrm{O} 12$ & 0.20474 & 0.26000 & 0.33594 & $\mathrm{O} 42$ & 0.10671 & 0.14329 & 0.32871 \\
\hline $\mathrm{O} 13$ & 0.23993 & 0.23993 & 0.33265 & $\mathrm{O} 43$ & 0.10296 & 0.10296 & 0.32450 \\
\hline
\end{tabular}


Table 3. Atomic coordinates for the faw (mep-t) framework, optimized as a silicate by GULP in cubic space group $P m \overline{3} n$, with $a=44.941 \AA$.

\begin{tabular}{|c|c|c|c|c|c|c|c|}
\hline Atom & $x$ & $y$ & $Z$ & Atom & $x$ & $y$ & $Z$ \\
\hline Si1 & 0.03387 & 0.41426 & 0.25055 & 016 & 0.10203 & 0.23231 & 0.22270 \\
\hline $\mathrm{Si} 2$ & 0.03387 & 0.35996 & 0.21005 & O17 & 0.05998 & 0.22134 & 0.21298 \\
\hline $\mathrm{Si} 3$ & 0.06521 & 0.30029 & 0.20322 & O18 & 0.08664 & 0.18763 & 0.19291 \\
\hline $\mathrm{Si} 4$ & 0.20050 & 0.20388 & 0.28557 & O19 & 0.09151 & 0.21594 & 0.09744 \\
\hline $\mathrm{Si} 5$ & 0.06534 & 0.23531 & 0.08808 & $\mathrm{O} 20$ & 0.08043 & 0.26564 & 0.08802 \\
\hline $\mathrm{Si} 6$ & 0.08609 & 0.20243 & 0.22337 & $\mathrm{O} 21$ & 0.04961 & 0.24817 & 0.06098 \\
\hline $\mathrm{Si} 7$ & 0.10717 & 0.14771 & 0.25728 & $\mathrm{O} 22$ & 0.04961 & 0.22238 & 0.11516 \\
\hline $\mathrm{Si} 8$ & 0.17608 & 0.26014 & 0.25680 & $\mathrm{O} 23$ & 0.13687 & 0.14655 & 0.27353 \\
\hline $\mathrm{Si} 9$ & 0.09259 & 0.32778 & 0.14769 & $\mathrm{O} 24$ & 0.10699 & 0.13269 & 0.22692 \\
\hline Si10 & 0.08795 & 0.09552 & 0.29596 & $\mathrm{O} 25$ & 0.09756 & 0.12162 & 0.27662 \\
\hline Si11 & 0.03388 & 0.20945 & 0.14223 & $\mathrm{O} 26$ & 0.14703 & 0.26117 & 0.23942 \\
\hline Si12 & 0.10680 & 0.11767 & 0.19656 & $\mathrm{O} 27$ & 0.09406 & 0.31187 & 0.11782 \\
\hline Si13 & 0.03387 & 0.24024 & 0.20258 & $\mathrm{O} 28$ & 0.11899 & 0.30878 & 0.15713 \\
\hline Si14 & 0.14539 & 0.28978 & 0.16667 & O29 & 0.07572 & 0.35704 & 0.15027 \\
\hline Si15 & 0.11797 & 0.26219 & 0.22203 & O30 & 0.06091 & 0.07972 & 0.30886 \\
\hline Si16 & 0.08718 & 0.17283 & 0.16244 & $\mathrm{O} 31$ & 0.06053 & 0.19114 & 0.15234 \\
\hline Si17 & 0.03387 & 0.26103 & 0.03387 & $\mathrm{O} 32$ & 0.03388 & 0.22485 & 0.17241 \\
\hline Si18 & 0.03387 & 0.46613 & 0.13506 & $\mathrm{O} 33$ & 0.00000 & 0.20945 & 0.14223 \\
\hline Si19 & 0.03387 & 0.41142 & 0.09511 & O34 & 0.09699 & 0.14525 & 0.17950 \\
\hline $\mathrm{Si} 20$ & 0.03387 & 0.38246 & 0.03387 & $\mathrm{O} 35$ & 0.13462 & 0.10243 & 0.18470 \\
\hline $\mathrm{Si} 21$ & 0.03387 & 0.06392 & 0.32175 & O36 & 0.00000 & 0.24024 & 0.20258 \\
\hline $\mathrm{Si} 22$ & 0.05884 & 0.38630 & 0.15285 & O37 & 0.13168 & 0.27599 & 0.19430 \\
\hline $\mathrm{Si} 23$ & 0.05800 & 0.44080 & 0.19308 & O38 & 0.03387 & 0.39694 & 0.06449 \\
\hline $\mathrm{O} 1$ & 0.03387 & 0.38711 & 0.23030 & O39 & 0.03387 & 0.38246 & 0.00000 \\
\hline $\mathrm{O} 2$ & 0.04654 & 0.42813 & 0.27874 & $\mathrm{O} 40$ & 0.00000 & 0.38246 & 0.03387 \\
\hline $\mathrm{O} 3$ & 0.00000 & 0.41426 & 0.25055 & O41 & 0.04890 & 0.35211 & 0.03387 \\
\hline $\mathrm{O} 4$ & 0.04594 & 0.42753 & 0.22182 & O42 & 0.00000 & 0.06392 & 0.32175 \\
\hline O5 & 0.00000 & 0.35996 & 0.21005 & O43 & 0.03387 & 0.04890 & 0.29139 \\
\hline O6 & 0.04954 & 0.33013 & 0.20664 & O44 & 0.05842 & 0.41355 & 0.17297 \\
\hline $\mathrm{O} 7$ & 0.04636 & 0.37313 & 0.18145 & $\mathrm{O} 45$ & 0.04636 & 0.39886 & 0.12398 \\
\hline $\mathrm{O} 8$ & 0.09159 & 0.28124 & 0.21263 & O46 & 0.04594 & 0.45347 & 0.16407 \\
\hline O9 & 0.04954 & 0.27027 & 0.20290 & O47 & 0.03387 & 0.26103 & 0.00000 \\
\hline $\mathrm{O} 10$ & 0.07890 & 0.31404 & 0.17546 & O48 & 0.00000 & 0.26103 & 0.03387 \\
\hline $\mathrm{O} 11$ & 0.18354 & 0.17464 & 0.28768 & O49 & 0.03387 & 0.43878 & 0.11509 \\
\hline $\mathrm{O} 12$ & 0.22185 & 0.22187 & 0.30475 & $\mathrm{O} 50$ & 0.00000 & 0.46613 & 0.13506 \\
\hline $\mathrm{O} 13$ & 0.22865 & 0.18998 & 0.27286 & O51 & 0.03387 & 0.50000 & 0.13506 \\
\hline $\mathrm{O} 14$ & 0.18829 & 0.23201 & 0.27119 & O52 & 0.00000 & 0.41142 & 0.09511 \\
\hline $\mathrm{O} 15$ & 0.09663 & 0.17507 & 0.24033 & & & & \\
\hline
\end{tabular}


Table 4. Atomic coordinates for the sod-t framework, optimized as a silicate by GULP in cubic space group $\operatorname{Im} \overline{3} m$, with $a=28.822 \AA$.

\begin{tabular}{|cccc|}
\hline Atom & $x$ & $y$ & $z$ \\
\hline Si1 & 0.05185 & 0.12720 & 0.44905 \\
Si2 & 0.05498 & 0.25724 & 0.33097 \\
Si3 & 0.10658 & 0.18106 & 0.37978 \\
O1 & 0.06258 & 0.16207 & 0.40749 \\
O2 & 0.08189 & 0.08189 & 0.44297 \\
O3 & 0.06037 & 0.15022 & 0.50000 \\
O4 & 0.00000 & 0.11001 & 0.44358 \\
O5 & 0.08002 & 0.29062 & 0.36736 \\
O6 & 0.00000 & 0.25136 & 0.34252 \\
O7 & 0.06040 & 0.27914 & 0.27914 \\
O8 & 0.08463 & 0.20941 & 0.33619 \\
O9 & 0.14120 & 0.14120 & 0.35987 \\
\hline
\end{tabular}


Table 5. Atomic coordinates for the fax framework, optimized by GULP as a silicate in hexagonal space group $P 6 / \mathrm{mmm}$, with $a=32.585 \AA$ and $c=33.764 \AA$.

\begin{tabular}{|cccc|}
\hline Atom & $x$ & $y$ & $z$ \\
\hline Si1 & 0.37543 & 0.05463 & 0.27343 \\
Si2 & 0.53138 & 0.15650 & 0.10571 \\
Si3 & 0.35200 & 0.12958 & 0.45645 \\
Si4 & 0.41614 & 0.05540 & 0.45693 \\
Si5 & 0.57225 & 0.23863 & 0.04603 \\
Si6 & 0.48025 & 0.05606 & 0.14182 \\
Si7 & 0.27403 & 0.08923 & 0.39607 \\
Si8 & 0.31595 & 0.05440 & 0.33816 \\
Si9 & 0.49400 & 0.20034 & 0.16867 \\
Si10 & 0.48368 & 0.05554 & 0.40040 \\
Si11 & 0.44940 & 0.10462 & 0.20799 \\
Si12 & 0.57561 & 0.24286 & 0.23142 \\
Si13 & 0.19360 & 0.05163 & 0.45650 \\
Si14 & 0.39854 & 0.11076 & 0.39684 \\
Si15 & 0.45722 & 0.10178 & 0.33695 \\
Si16 & 0.52824 & 0.14861 & 0.27258 \\
O1 & 0.22538 & 0.05705 & 0.41866 \\
O2 & 0.33938 & 0.16969 & 0.46475 \\
O3 & 0.47547 & 0.23774 & 0.15865 \\
O4 & 0.44689 & 0.12957 & 0.37217 \\
O5 & 0.51141 & 0.18360 & 0.13137 \\
O6 & 0.49497 & 0.09809 & 0.10761 \\
O7 & 0.52946 & 0.05892 & 0.15610 \\
O8 & 0.44380 & 0.00000 & 0.12835 \\
O9 & 0.41353 & 0.07060 & 0.30829 \\
O10 & 0.39961 & 0.08109 & 0.23218 \\
O11 & 0.45975 & 0.00000 & 0.40520 \\
O12 & 0.55494 & 0.20467 & 0.26626 \\
O13 & 0.46933 & 0.06497 & 0.35734 \\
O14 & 0.30020 & 0.00000 & 0.34789 \\
\hline & & & \\
\hline
\end{tabular}

\begin{tabular}{|cccc|}
\hline Atom & $x$ & $y$ & $z$ \\
\hline O15 & 0.35519 & 0.00000 & 0.26397 \\
O16 & 0.54024 & 0.08049 & 0.40282 \\
O17 & 0.55979 & 0.23122 & 0.00000 \\
O18 & 0.45423 & 0.06935 & 0.17658 \\
O19 & 0.27480 & 0.06531 & 0.35340 \\
O20 & 0.46769 & 0.07625 & 0.43676 \\
O21 & 0.62421 & 0.24842 & 0.21454 \\
O22 & 0.56459 & 0.12918 & 0.27548 \\
O23 & 0.42274 & 0.07945 & 0.50000 \\
O24 & 0.39907 & 0.14927 & 0.42801 \\
O25 & 0.50147 & 0.14176 & 0.31360 \\
O26 & 0.62743 & 0.25485 & 0.05373 \\
O27 & 0.45281 & 0.15192 & 0.18878 \\
O28 & 0.31155 & 0.08990 & 0.42825 \\
O29 & 0.28326 & 0.14163 & 0.38687 \\
O30 & 0.53887 & 0.18535 & 0.06454 \\
O31 & 0.58258 & 0.16517 & 0.12054 \\
O32 & 0.49305 & 0.11942 & 0.23728 \\
O33 & 0.53935 & 0.22728 & 0.19587 \\
O34 & 0.14836 & 0.00000 & 0.45491 \\
O35 & 0.17301 & 0.08651 & 0.45211 \\
O36 & 0.35627 & 0.11014 & 0.50000 \\
O37 & 0.39103 & 0.00000 & 0.46192 \\
O38 & 0.56380 & 0.28190 & 0.06172 \\
O39 & 0.58492 & 0.29246 & 0.24939 \\
O40 & 0.38531 & 0.06715 & 0.42700 \\
O41 & 0.33321 & 0.06345 & 0.29145 \\
O42 & 0.35929 & 0.09273 & 0.36333 \\
O43 & 0.21980 & 0.06006 & 0.50000 \\
& & & \\
\hline & & & \\
\hline
\end{tabular}


Table 6. Atomic coordinates for the fay framework, optimized as a silicate by GULP in tetragonal space group $F d \overline{3} m$, with $a=23.575 \AA$ and $c=40.327 \AA$.

\begin{tabular}{|c|c|c|c|c|c|c|c|}
\hline Atom & $x$ & $y$ & $Z$ & Atom & $x$ & $y$ & 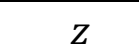 \\
\hline Sil & 41016 & 50367 & 415 & O13 & 97307 & 0.27660 & 124 \\
\hline $\mathrm{Si} 2$ & 64 & 862 & & & 01224 & 34857 & 0.22377 \\
\hline $\mathrm{Si3}$ & 5090 & 3673 & & & 1787 & 34470 & 21227 \\
\hline $\mathrm{Si} 4$ & 1038 & 24985 & & & & 40156 & 16996 \\
\hline Si5 & & & & 17 & 11 & & 278 \\
\hline Si6 & 68 & 77 & 0 & 18 & 76 & 87 & 0.254 \\
\hline $\mathrm{Si} 7$ & 81 & & 0 & 19 & 51 & 526 & 0.2 \\
\hline $\mathrm{Si} 8$ & 39 & & 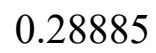 & 20 & 31 & & 0.32040 \\
\hline Si9 & & 0 & & & & 27 & 0.2730 \\
\hline Si 10 & 91 & 0. & & 22 & & & 0.2 \\
\hline Si11 & 70 & 0 & & 23 & & 0.4 & \\
\hline Si12 & 0 . & 0 . & & 24 & & 0.5 & 0.2 \\
\hline Si13 & 0 . & 0 & & 25 & 0.3 & 0.4 & 0.2 \\
\hline Si14 & 0. & 0 & & 26 & 0.2 & 0.4 & 0.2 \\
\hline Si15 & 0. & 0. & 0.3 & 27 & 0.0 & 0.2 & 0.2 \\
\hline Si16 & 0. & 0. & 0 & 28 & 0.1 & 0.2 & 0.3 \\
\hline Sil7 & 0. & 0.46 & 0 & 29 & 0.0 & 0.3 & 0.3 \\
\hline Si 18 & 0.2 & 0.41 & 0 & 30 & 0.2 & 0.2 & 0.33908 \\
\hline $\mathrm{O} 1$ & 0. & 0. & & 31 & & & 0.3 \\
\hline $\mathrm{O} 2$ & & & & & & & \\
\hline $\mathrm{O} 3$ & & & & O33 & & & 0000 \\
\hline $\mathrm{O} 4$ & 0.39 & & & O34 & 0.22309 & 0.35192 & 0.4543 \\
\hline O5 & 0.38041 & 0.38041 & 0.45197 & O35 & 0.13934 & 0.30152 & 0.43561 \\
\hline O6 & 0.37445 & 0.45545 & 0.50000 & 036 & 0.15262 & 0.40032 & 0.3956 \\
\hline O7 & 0.28401 & 0.43294 & 0.46676 & $\mathrm{O} 37$ & 0.06163 & 0.35562 & 0.3937 \\
\hline O8 & 0.03540 & 0.11930 & & $\mathrm{O} 38$ & 0.96662 & 0.41883 & 0.37612 \\
\hline O9 & & 0.11304 & & O39 & 0.05550 & 0.46476 & 0.3636 \\
\hline $\mathrm{O} 10$ & & & & & & 0.37 & 0.1058 \\
\hline $\mathrm{O} 1$ & & & & & & 0.4 & 0.439 \\
\hline $\mathrm{O} 12$ & 0.05120 & 0.29310 & 0.17158 & $\mathrm{O} 42$ & 0.18944 & 0.42569 & 0.50000 \\
\hline
\end{tabular}



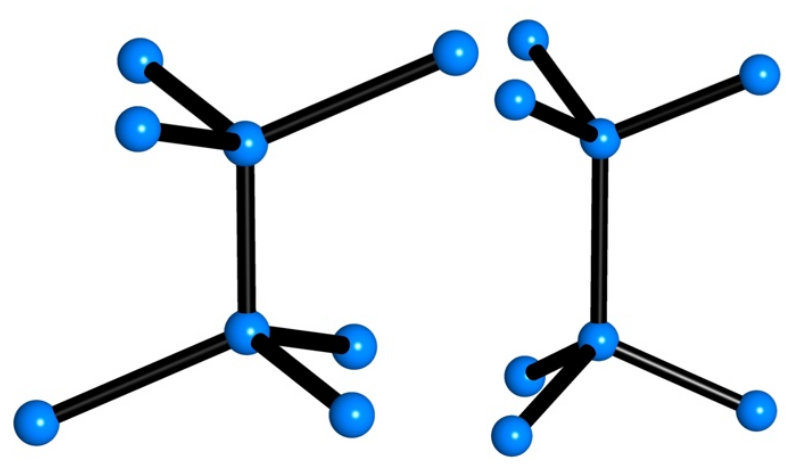

eclipsed

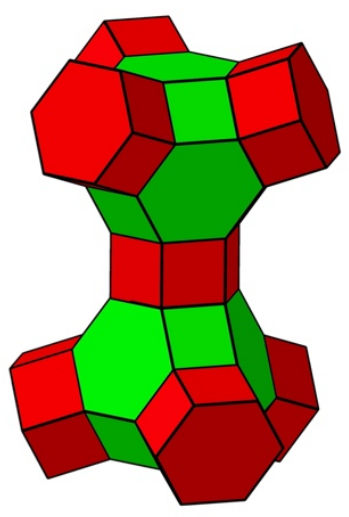

staggered

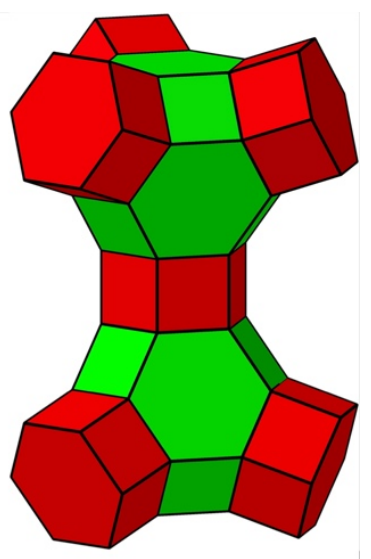

eclipsed

Figure 1. (Left) Illustration of the staggered and eclipsed configurations in tetrahedral nets, and (right) in expanded form as two joined $\mathrm{SP}_{4}$ tetrahedral units $(\mathrm{S} \equiv$ sodalite cage, $\mathrm{P} \equiv$ hexagonal prism). The tetrahedral nets of the staggered and eclipsed configurations of the $\mathrm{SP}_{4}$ forms experience no torsional strain about the $\mathrm{S}-\mathrm{P}-\mathrm{S}$ axes. The $\mathrm{P}-\mathrm{S}-\mathrm{P}$ angle is the tetrahedral angle, $109.47^{\circ}$, and the $\mathrm{S}-\mathrm{P}-\mathrm{S}$ angle is $180^{\circ}$. 


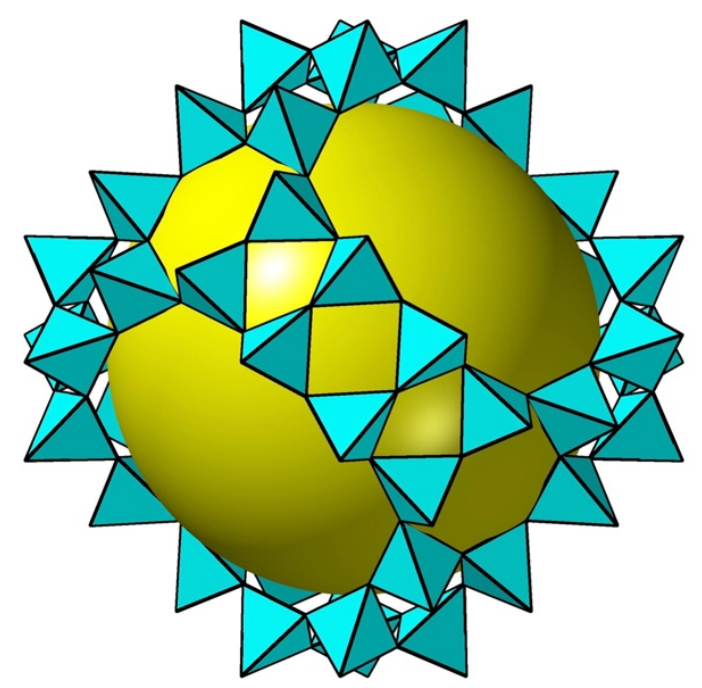

FAU

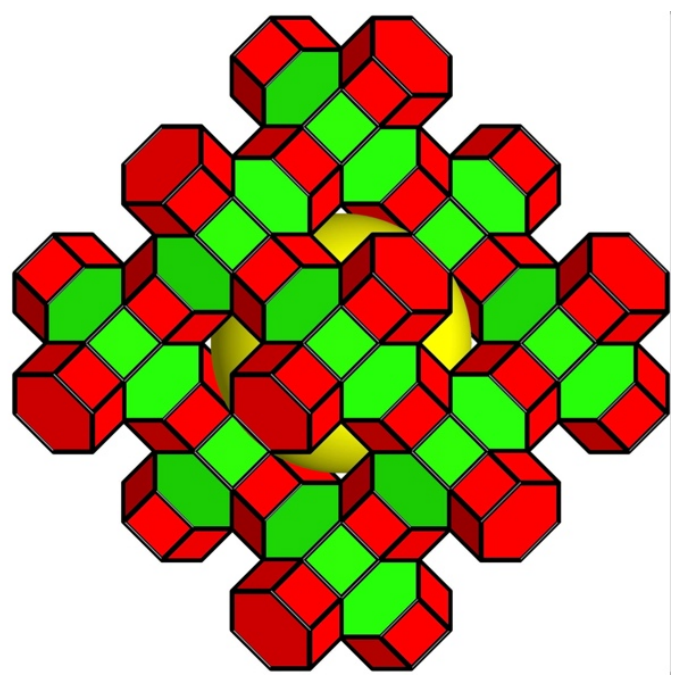

Figure 2. The FAU cage formed by linked $\mathrm{SiO}_{4}$ tetrahedra (left) and by the augmented cristobalite -t net represented as $\mathrm{SP}_{4}$ tetrahedral units (right). The maximum included sphere is represented by the yellow ball. 

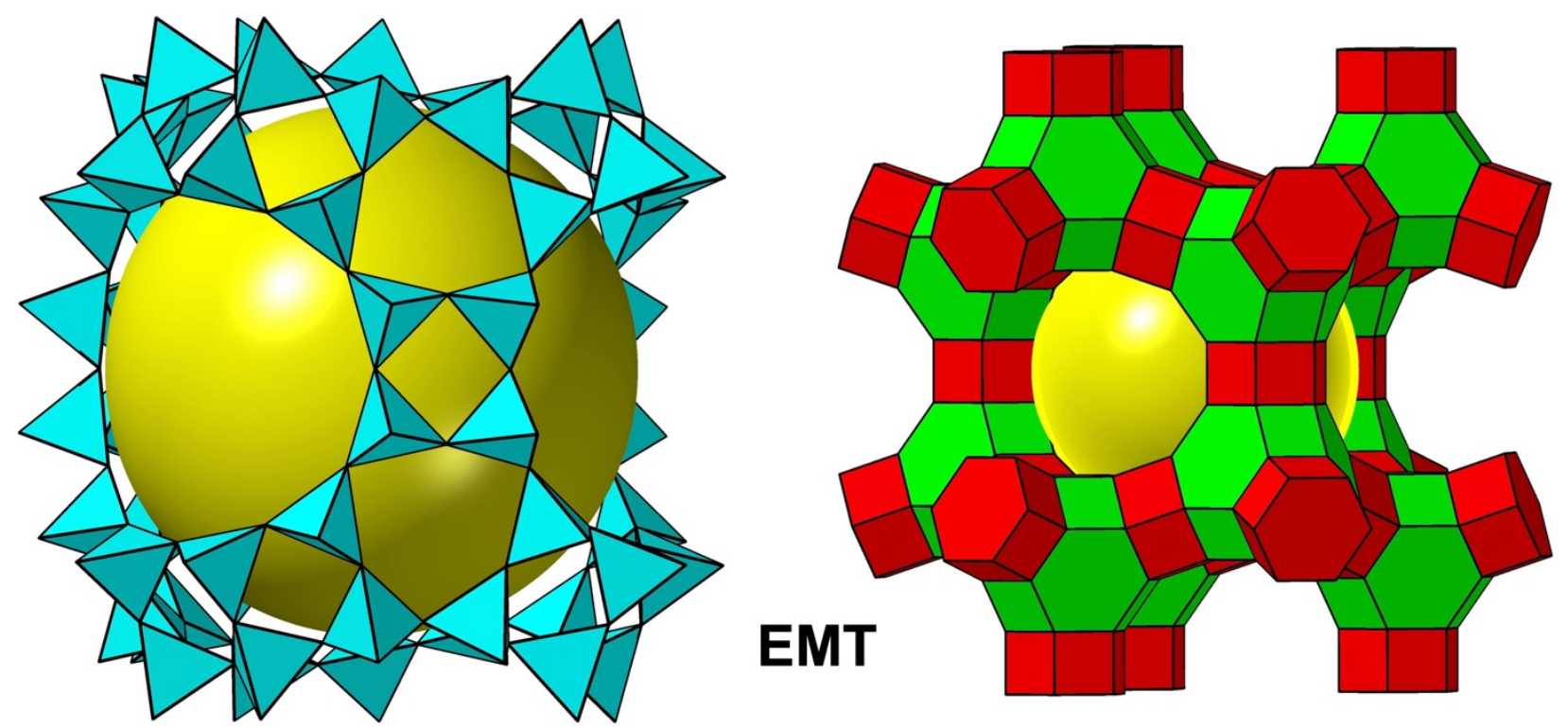

Figure 3. The EMT cage formed by linked $\mathrm{SiO}_{4}$ tetrahedra (left) and by the augmented lonsdaleite -t net, represented as $\mathrm{SP}_{4}$ tetrahedral units (right). The maximum included sphere is represented by the yellow ball. 


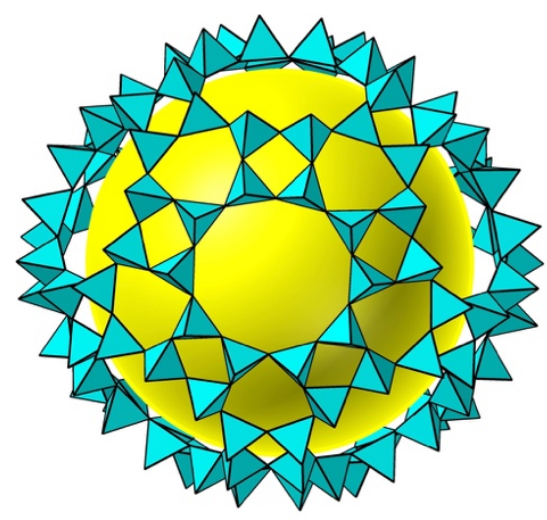

fav, faw smaller cage



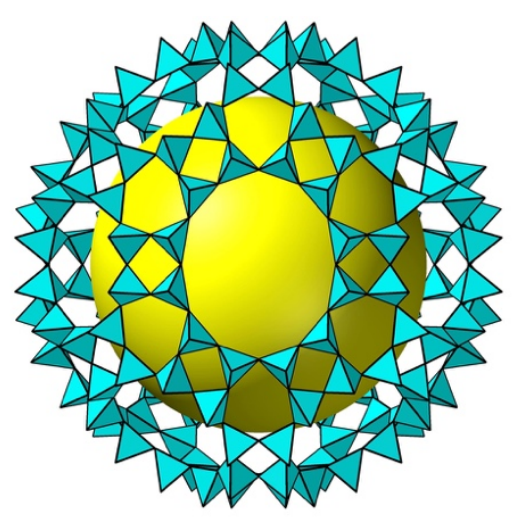

faw larger cage

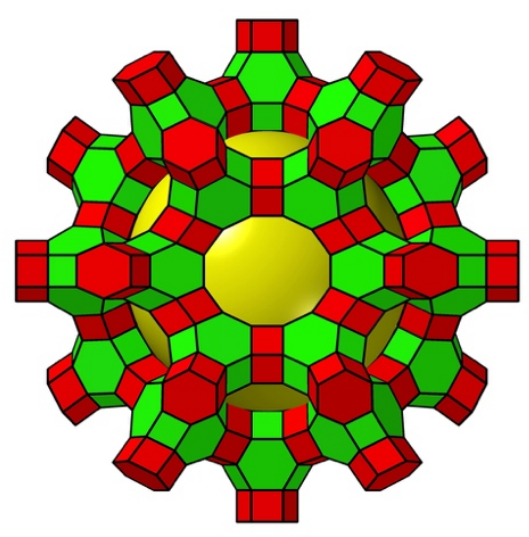

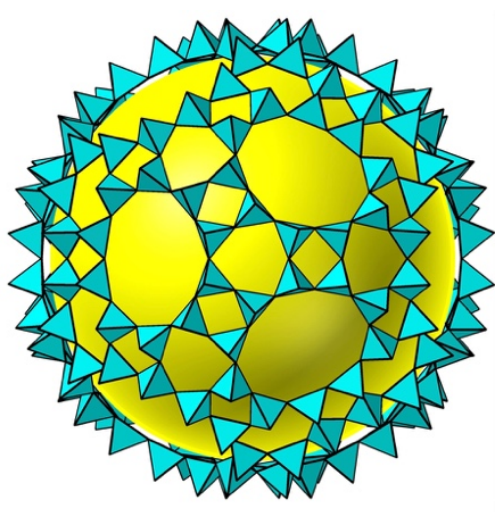

fav larger cage

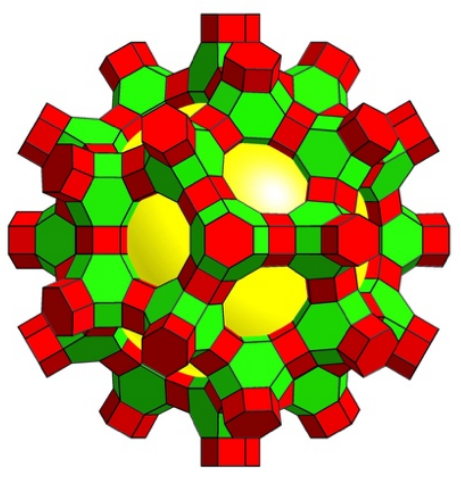

Figure 4. The cages in fav and faw delineated by linked $\mathrm{SiO}_{4}$ tetrahedra (top) and depicted as linked $\mathrm{SP}_{4}$ tetrahedral units (bottom). The maximum included sphere is represented by the yellow ball. 


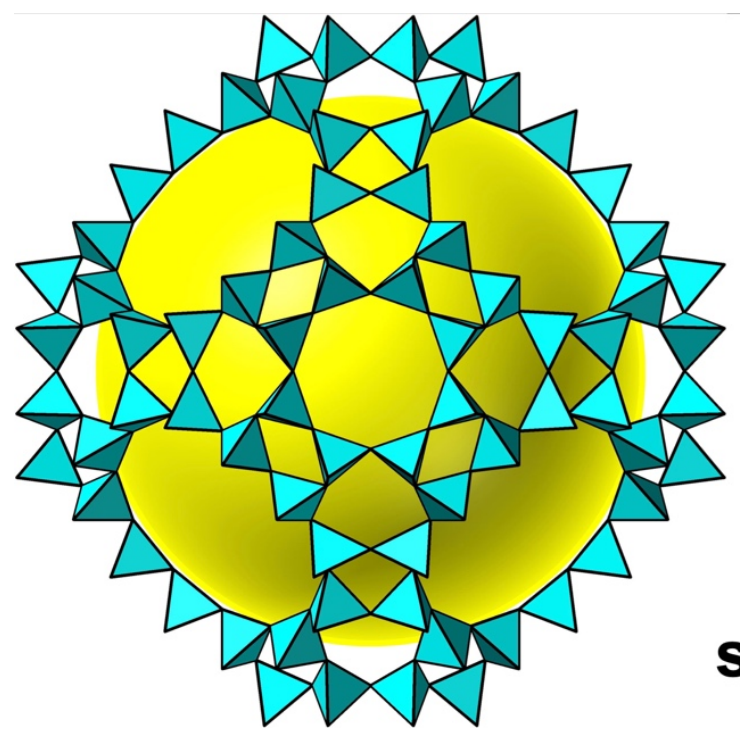

sod-t

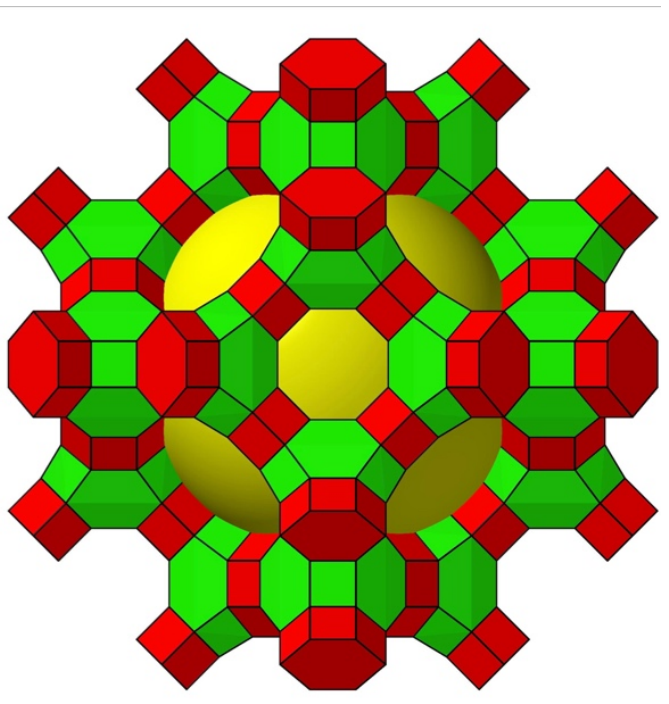

Figure 5. The cage in sod-t formed outlined by linked $\mathrm{SiO}_{4}$ tetrahedra (left) and shown as linked $\mathrm{SP}_{4}$ tetrahedral units (right). The maximum included sphere is represented by the yellow ball. 


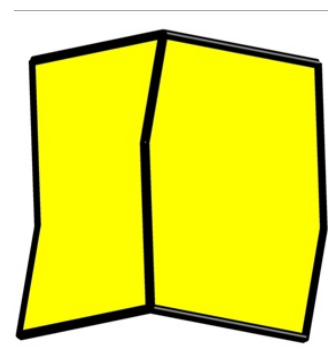

dia (ada)
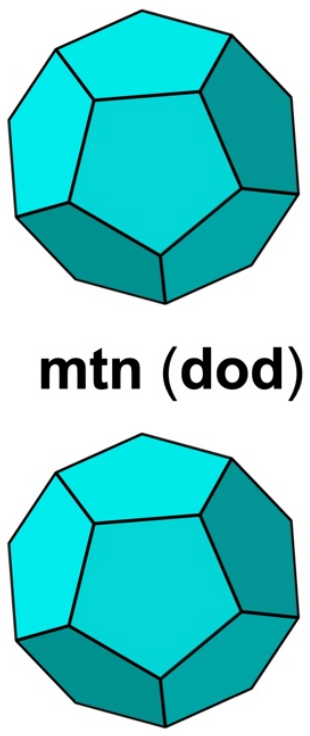

mep (dod)

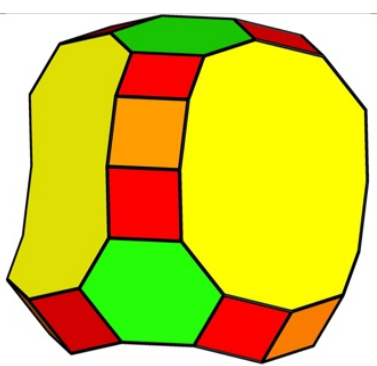

fau (fac)

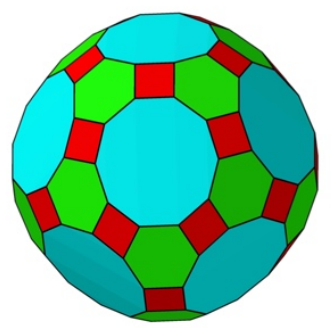

fav (ild)

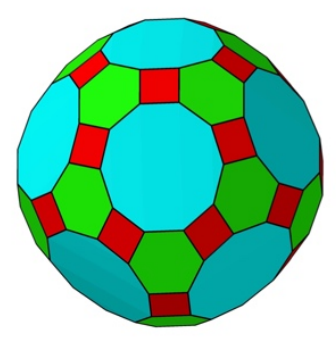

faw (ild)

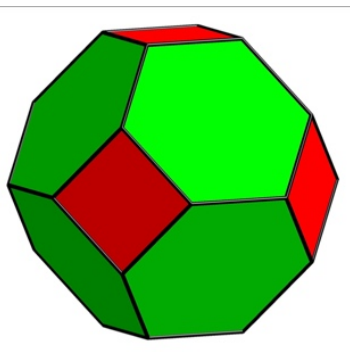

sod (tro) sod-t (tro-e-a)
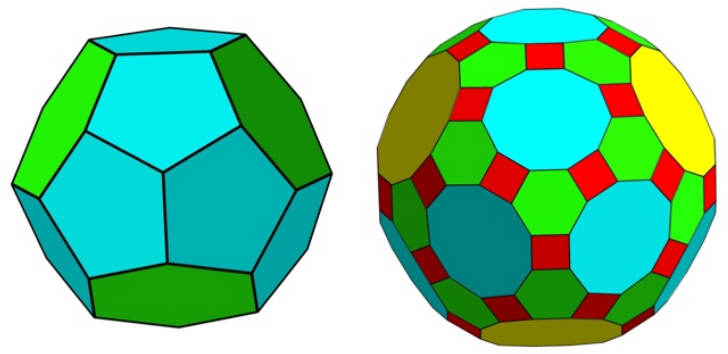

mtn (mcp-d) fav (mcp-d-e-a)

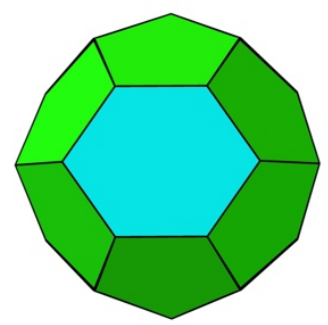

mep (fkt-d)

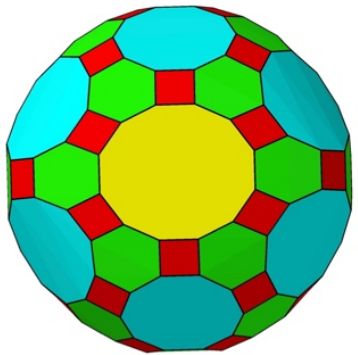

faw (fkf-d-e-a)

Figure 6. Illustration of the polyhedral units defining cages in various nets. Symbols in parentheses are RCSR symbols for individual polyhedra. 


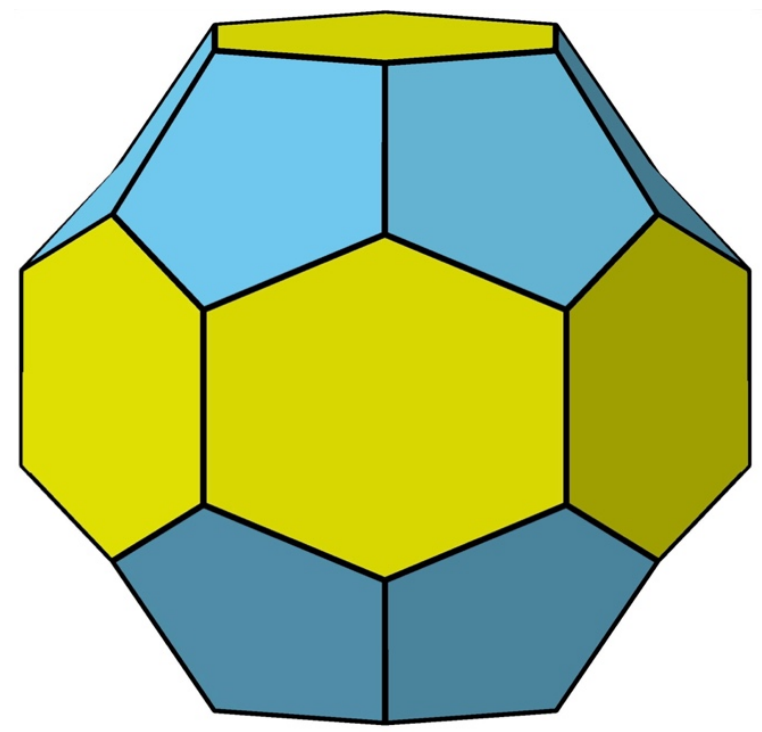

alb-x-d (hxb)

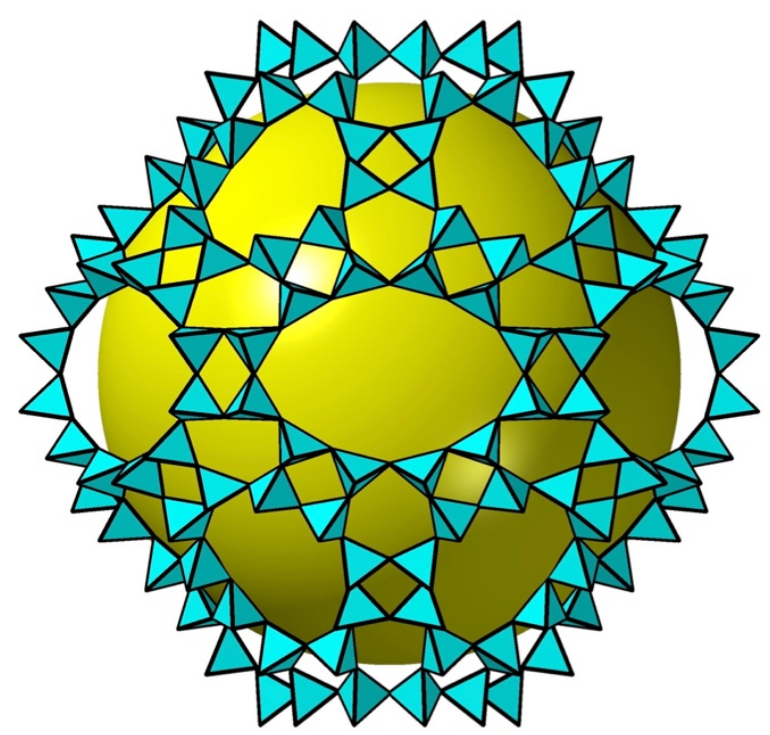

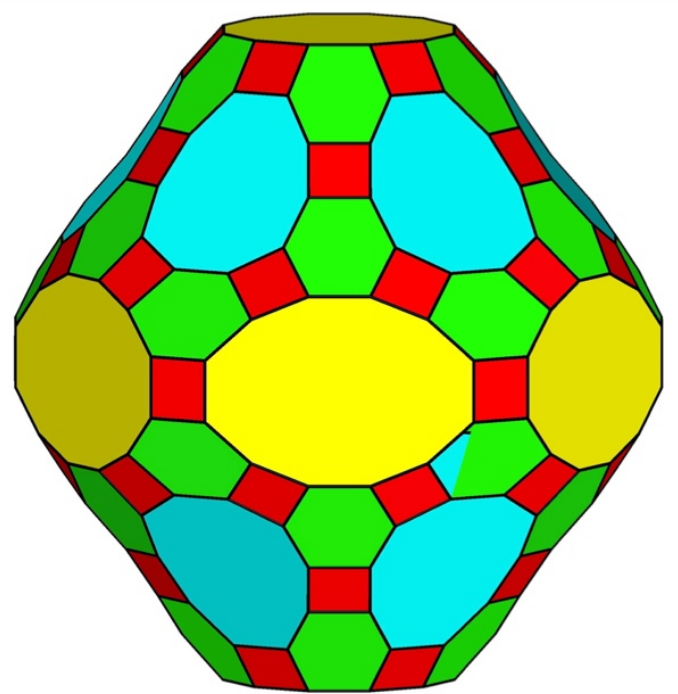

$\operatorname{fax}(\mathrm{fxc})$

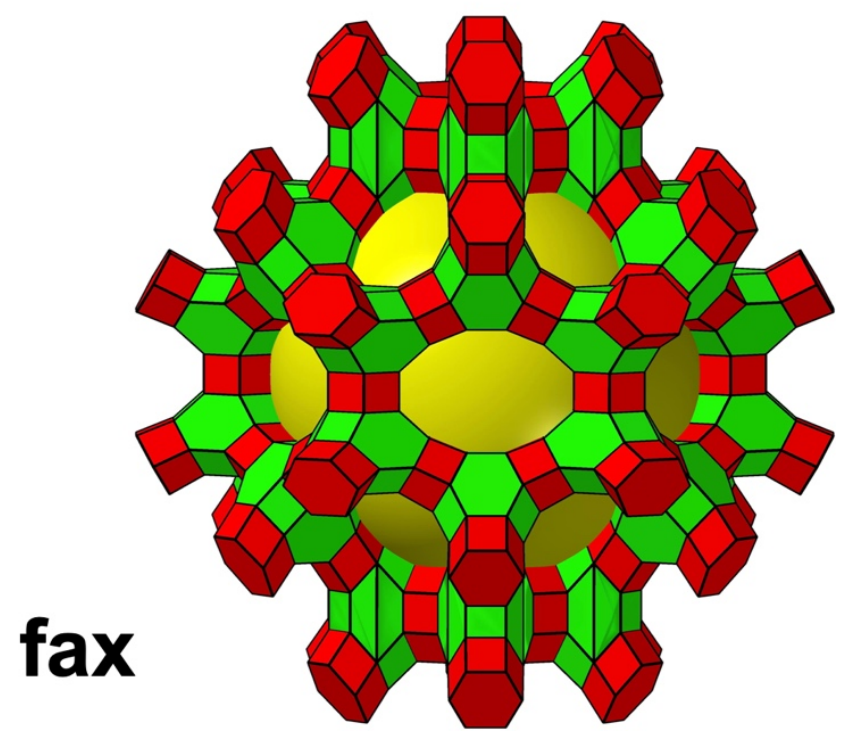

Figure 7. Top row: The polyhedral units (symbols in parentheses) defining cages in alb-x-d and for the augmented fax framework. Bottom row: The cage in fax shown as linked $\mathrm{SiO}_{4}$ tetrahedra (left) and shown as linked $\mathrm{SP}_{4}$ tetrahedral units (right). The maximum included sphere is represented by the yellow ball. Distortion of the $\mathrm{SP}_{4}$ units is visible. 


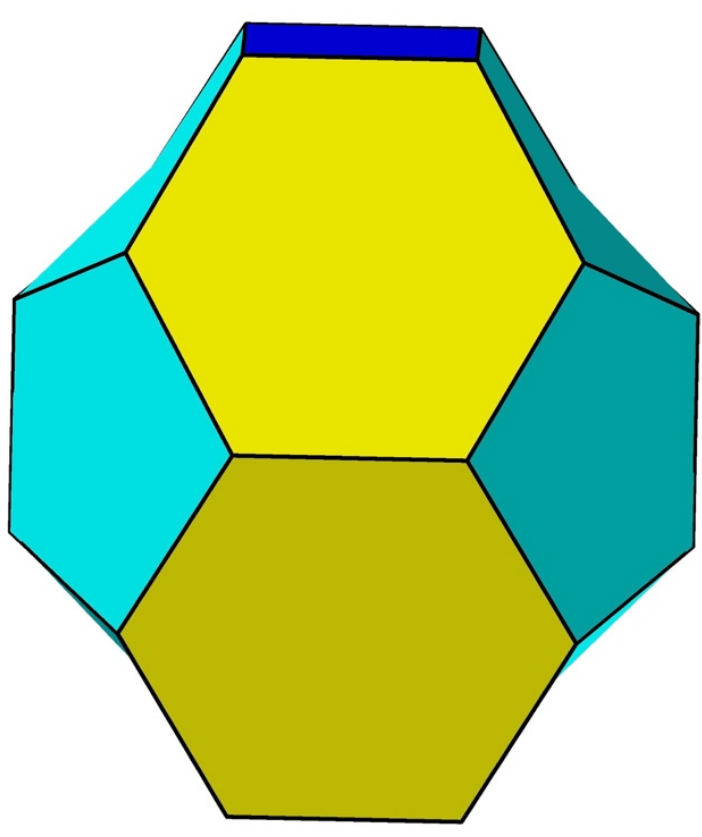

csj (wsf)

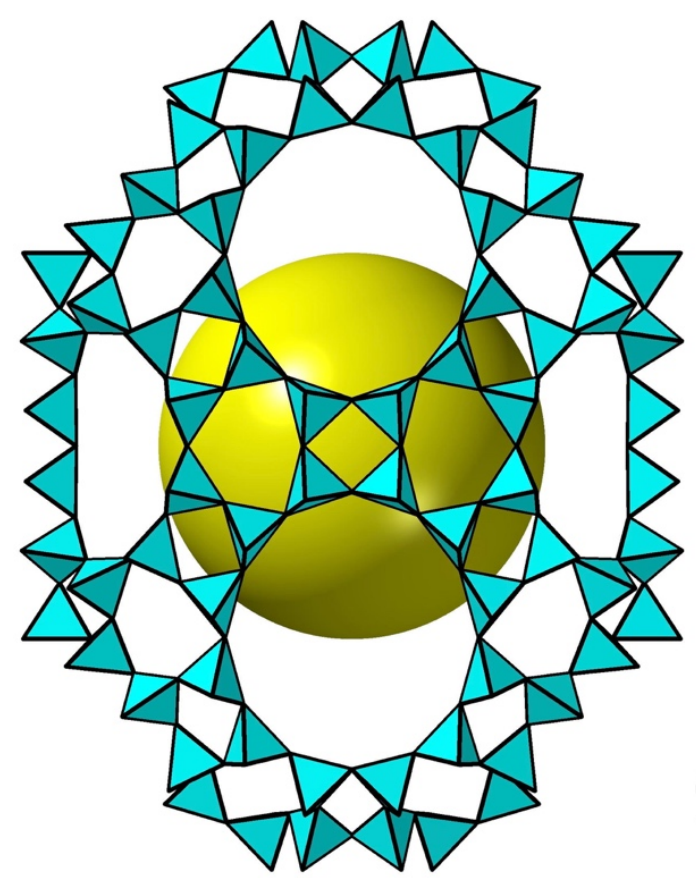

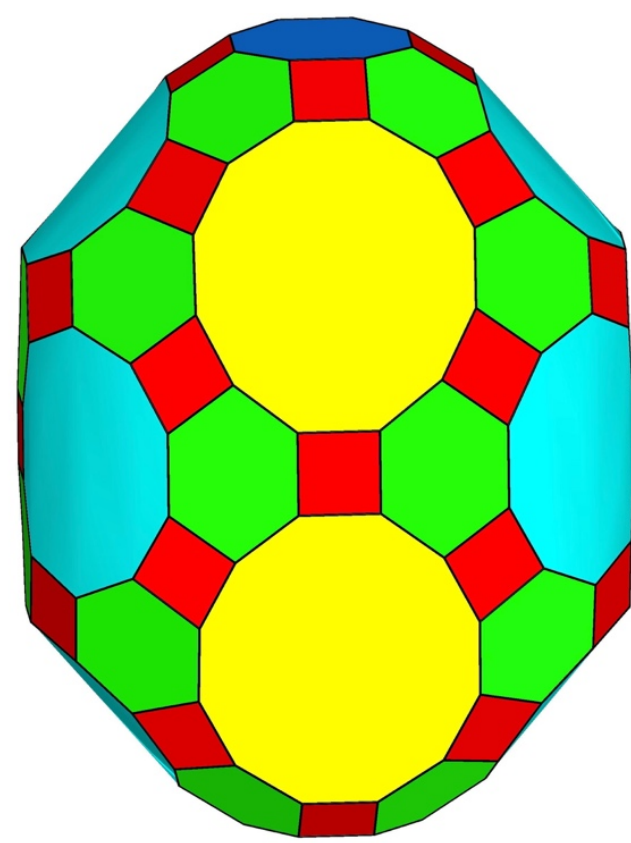

fay (fyc)

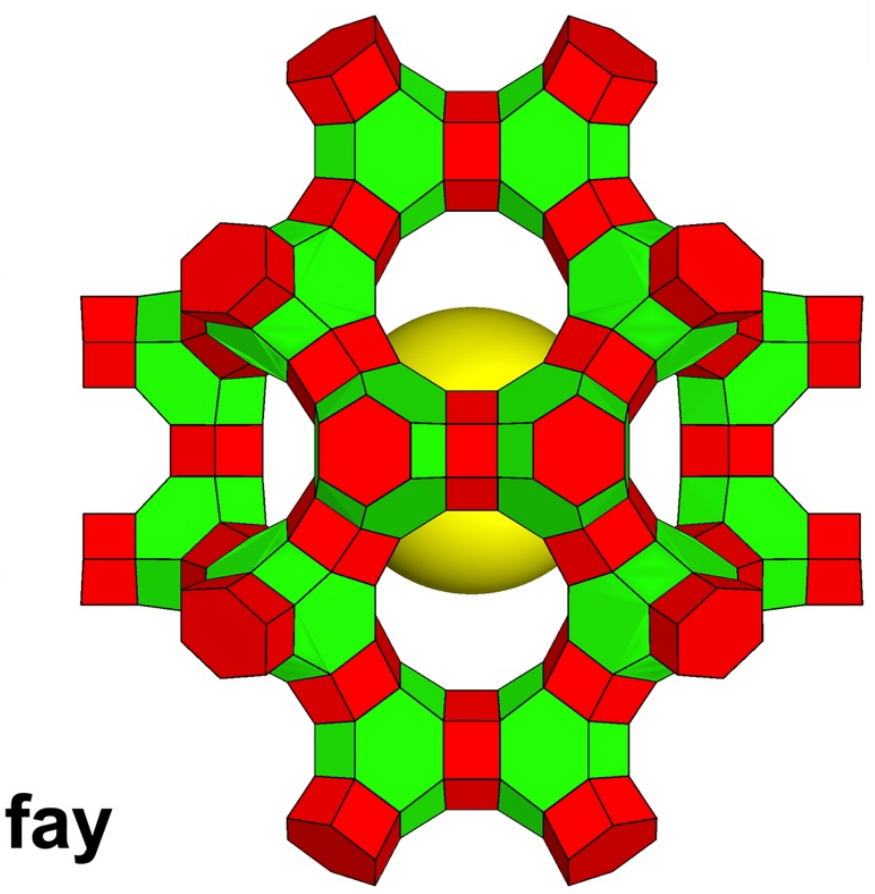

Figure 8. Top row: The polyhedral units (symbols in parentheses) defining cages in csj and for the augmented fay framework. Bottom row: The ellipsoidal cage in fay shown as linked $\mathrm{SiO}_{4}$ tetrahedra (left) and as linked $\mathrm{SP}_{4}$ tetrahedral units (right). The maximum included sphere is represented by the yellow ball: the sphere diameter is limited by the ellipsoidal cage. Strong distortion of some of the $\mathrm{SP}_{4}$ units is visible. 